\title{
POTENSI INTEGRASI KEARIFAN LOKAL DAYAK DALAM PEMBELAJARAN ILMU PENGETAHUAN ALAM DI SEKOLAH DASAR KOTA PALANGKA RAYA
}

\author{
Sakman ${ }^{1}$, Kristiani Natalina ${ }^{2}$ \\ ${ }^{1}$ PPKn, FKIP, Universitas Palangka Raya \\ ${ }^{2}$ PGSD, FKIP, Universitas Palangka Raya
}

Correspondence author: Sakman, email: Sakman@fkip.upr.ac.id

DOI: https://doi.org/10.37012/jipmht.v4i1.198

\begin{abstract}
ABSTRAK
Fokus studi ini adalah untuk mengidentifikasi sifat pandangan dunia yang dianut oleh calon guru pendidikan dan mengeksplorasi hubungan, jika ada, antara pandangan dunia mereka dan konsepsi mereka tentang sifat sains. Selain itu, implikasi dari hubungan ini untuk pengajaran dan pembelajaran sains dibahas. Pesertanya adalah 30 calon guru IPA Dayak. Konsepsi mereka tentang ilmu pengetahuan alam dan pandangan dunia mereka yang spesifik tentang hubungan manusia dengan alam dinilai menggunakan kuesioner yang berhubungan dengan wawancara lanjutan. Hasil penelitian menunjukkan bahwa $70 \%$ dari peserta, terlepas dari latar belakang budaya mereka, memiliki pandangan dunia yang berpusat pada alam, sementara $30 \%$ dari mereka memiliki pandangan dunia antroposentris. Dan hasil wawancara menegaskan bahwa partisipan memiliki pandangan sempit tentang hakikat sains, dimana mereka mendeskripsikan sains hanya berdasarkan fakta, berpusat pada observasi, tidak kreatif dan tentatif karena perubahan fakta. Studi ini menyarankan perlunya memasukkan perspektif sosiokultural dan sifat sains dalam kurikulum.
\end{abstract}

Kata Kunci: worldview, sifat IPA, kearifan lokal

\begin{abstract}
The focus of the study was to identify the nature of worldview held by candidate science teacher, and explores the relationship, if any, between their worldview and their conception of nature of science. In addition, the implication of this relationship for science teaching and learning are discussed. Participants were 30 Dayak prospective science teachers. Their conception of nature $f$ science and their worldview specific to humans' relationship with the natural world were assessed using a questionnaire in conjunction with follow up interviews. The results show that $70 \%$ of the participant, irrespective to their cultural backgrounds, hold the nature centric worldview, while 30\% of them have the anthropocentric worldview. And the interview result confirm that participants possessed narrow view about the nature of science, where they described science as based on facts only, core on observation, no creativity and tentative due to the change of facts. The study suggests the need to for incorporating sociocultural perspectives and nature of science in the curriculum.
\end{abstract}

Keywords: worldview, sifat IPA, kearifan lokal

\section{PENDAHULUAN}

Penelitian yang telah dilakukan dalam ranah penguasaan konsep pembelajaran Imu Pengetahuan Alam (IPA), telah menstimulasi ketertarikan peneliti untuk meneliti lebih lanjut pada dua area studi: bagaimana siswa bergerak antara dunia mereka sehari-hari dengan dunia IPA di sekolah, dan bagaimana siswa menghadapi konflik kognitif di antara dua dunia tersebut. Salah satu masalah dalam pendidikan IPA yang teridentifikasi pada siswa di Negara berkembang yaitu adanya perasaan bahwa IPA disekolah lebih seperti budaya asing bagi mereka (Maddock, 1981). Perasaan tersebut muncul dikarenakan perbedaan yang mendasar antara kebudayaan IPA barat dengan kebudayaan asli di daerah mereka (Aikenhead, 1997; Jegede, 1995). Perbedaan ini berpotensi dalam menimbulkan kesenjangan antara IPA ilmiah dengan IPA lokal. Yang tentunya kemudian akan berimbas 
pula pada rendahnya kualitas pembelajaran IPA di Sekolah Dasar (SD).

Kualitas pembelajaran IPA yang rendah dapat terlihat dari berbagai kejadian atau gejala yang dialami masyarakat sehari-hari. Banyak tingkah laku masyarakat pada sekarang ini, yang menunjukkan seakan-akan pendidikan IPA yang pernah mereka dapatkan di sekolah tidak berdampak dalam cara hidup dan cara berpikir mereka. Sebagai contoh permasalahan kabut asap yang terjadi di daerah Palangka Raya. Rasyid (2014) dalam penelitiannya menyebutkan bahwa kebakaran hutan dan lahan terjadi disebabkan oleh 2 (dua) faktor utama yaitu faktor alami dan faktor kegiatan manusia yang tidak terkontrol. Faktor alami antara lain oleh pengaruh El-Nino yang menyebabkan kemarau berkepanjangan sehingga jumlah air dalam tanah berkurang yang dapat mendukung mudah terbakarnya tanah gambut. Selain itu faktor kegiatan manusia yang mebuka lahan dengan teknik tebang-tebas-bakar yang tidak terkontrol, biasa dilakukan oleh perusahaan HTI (Hutan Tanaman Industri) dan peladang berpindah ataupun menetap. Ataupun pembakaran secara disengaja untuk mendapatkan lapangan penggembalaan atau tempat berburu. Hal ini menandakan adanya oknum yang melakukan pembakaran hutan. Yang walaupun mereka dahulunya adalah siswa SD yang tentunya pernah mendapatkan pendidikan mengenai dampak dari kebakaran hutan, tetapi tidak mampu mengubah sikap mereka terhadap alam sekitar.

Siswa nampaknya memiliki cara tersendiri dalam menghadapi konflik kognitif yang muncul terhadap konsep IPA yang mereka pelajari di kelas dengan norma asli, nilai, kepercayaan, dan tindakan konvensional yang biasa mereka lakukan dalam kehidupan sehari- hari. Tindakan yang mereka hasilkan dan pola pikir merekadari gejala yang muncul di atas membuktikan hal tersebut. Berdasarkan analisis singkat dari Costa (1995), peneliti meyakini bahwa dasar dari "puncak gunung es" yang terlihat dari gejala adaya oknum yang terlibat dalam kasus kabut asap di Palangka Raya, adalah adanya ketidakmampuan pelaku dalam melintasi batasan budaya mereka sehari-hari untuk masuk dalam budaya ilmiah. Hal ini dikarenakan ada perasaan asing terhadap budaya ilmiah dan adanya nilai-nilai kebudayaan yang tidak relevan menurut pandangannya. Hasil dari penolakan mereka terhadap apa yang mereka yakini tersebutlah yang membentuk perilaku orang tersebut.

Menggali dan memanfaatkan kearifan lokal yang tepat dalam dalam pembelajaran IPA diyakini dapat menjadi jembatan yang tepat untuk menghubungkan kesenjangan budaya yang muncul. Daerah Kalimantan Tengah terutama terkenal dengan budaya dayaknya yang kental, seharusnya nilai-nilai yang telah diajarkan turun temurun dalam sebuah keluarga ini tidak begitu saja dihilangkan dan di anggap tidak relevan dalam proses belajar mengajar di sekolah, sebaliknya ketika seorang calon guru memiliki kemampuan untuk menemukan dan menggali potensi yang ada dalam kearifan lokal, maka pembelajaran akan menjadi lebih bermakna dan kontekstual bagi siswa.

Hal ini penting untuk mengurangi konflik kognitif yang akan muncul dan mencegah terbentuknya siswa dengan keadaanyang tidak siap dan tidak mampu melakukan proses inkulturasi.

Penelitian dengan tema ini telah banyak dikembangkan dengan menggunakan sampel siswa-siswa yang tidak pernah terekpsos budaya Barat. Namun eksplorasi lebih spesifik terhadap guru-guru yang tidak memiliki latar belakang budaya Barat masihlah sangat kurang. Sehingga dalam penelitian ini, peneliti fokus kepada guru dan calon guru di 
Palangka Raya yang mengajar IPA pada tingkat sekolah dasar. Kerangka teori yang dipaparkan di atas akan digunakan dalam penelitian ini untuk mencoba menggali lebih dalam mengenai apa yang terjadi dalam proses berfikir guru, sebagai yang berperan penting dalam proses transfer pengetahuan di dalam kelas IPA.

\section{METODE PENELITIAN}

Jenis penelitian yang digunakan adalah penelitian kualitatif, dengan menggunakan pendekatan case-oriented understanding. Lokasi penelitian di Sekolah Dasar yang ada di Kota Palangka Raya dan PGSD UNPAR. Lama penelitian adalah selama 1 (satu) tahun yaitu 1 Januari 2017 hingga 31 Desember 2017. Partisipan dalam penelitian ini adalah mahasiswa calon guru SD yang mengikuti mata kuliah IPA serta guru sekolah dasar di Kota Palangka Raya.

Teknik pengumpulan data dalam penelitian ini adalah dengan menggunakan lembar kuesioner, observasi partisipatif dan wawancara mendalam ditambah dengan kajian dokumen, yang bertujuan tidak hanya untuk menggali data, tetapi juga untuk mengungkap makna yang terkandung dalam latar penelitian. Semua data akan dikumpulkan untuk dilakukan proses reduksi data, penyajian data dan analisis melalui teknik Content Analysis, untuk kemudian dilanjutkan dengan proses penarikan kesimpulan.

\section{HASIL DAN PEMBAHASAN}

\section{Konsep kognitif terhadap hubungan manusia-Alam}

Dalam kuesioner ini ada sebanyak lima item pertanyaan yang ditanyakan kepada peserta. Item \#1 dari questionaire ini meminta partisipan untuk mendeskripsikan impresi mereka terhadap alam, item \#2 dan \#3 berfokus kepada pandangan partisipan mengenai bagaimana manusia memperoleh pengetahuan mengenai alam sekitar. Sedangkan item \#4 dan \#5 menanyakan secara langsung pendapat partisipan mengenai interaksi antara manusia dan alam sekitar.

Setelah dilakukan analisis terhadap respons partisipan mengenai worldview mereka, diperoleh tiga dimensi. Dimensi pertama adalah sebuah bentuk kesadaran partisipan terhadap dirinya sebagai individu yang terpisah dari alam. Dalam hal ini, pandangan partisipan, mengenai bagaimana dan mengapa manusia memperoleh pengetahuan mengenai alam, akan di analisis. Dimensi kedua adalah gambaran partisipan mengenai alam. Hal yang akan dianalis adalah pada pemahaman mengenai apa yang dipikirkan partisipan pada saat mereka memilih istilah yang mereka pergunakan untuk mendeskrisikan mengenai alam. Analisis ini kemudian akan menyediakan gambaran umum terhadap persepsi partisipan mengenai peran manusia di alam dan definisi mereka mengenai alam yang kemudian merujuk kepada dimensi ketiga, yang berkaitan dengan hubungan kehidupan manusia terhadap alam. Kajian mendalam terhadap profil yang mewakili worldview partisipan sebagai individu akan dikemukakan pada bagian kesimpulan dari analisis.

Respon partisipan pada dimensi pertama akan dijelaskan pada Tabel 1, yaitu mengenai bagaimana dan mengapa manusia mempelajari alam sekitarnya. Penjelasan dari kategori yang dimaksud disertai dengan jumlah frekuensi respons dari partisipan dan contoh kutipan jawaban peserta. Perlu diketahui bahwa respons dari satu partisipan dapat berada pada satu atau lebih kategori. 
Tabel 1.

Persepsi Partisipan mengenai bagaimana dan mengapa manusia mempelajari tentang Alam (Peran manusia)

\begin{tabular}{|l|c|l|}
\hline \multicolumn{1}{|c|}{ Kategori dan deskripsi } & $\begin{array}{c}\text { Frekuensi } \\
\text { respons }\end{array}$ & \multicolumn{1}{|c|}{ Contoh kutipan Jawaban } \\
\hline $\begin{array}{l}\text { Manusia memperoleh manfaat dari } \\
\text { alam }\end{array}$ & 2 & $\begin{array}{l}\text { "Manusia dan Alam memiliki hubungan timbal balik } \\
\text { yang saling menguntungkan. Manusia tidak dapat } \\
\text { tinggal jika tidak ada Alam" (partisipan 4) }\end{array}$ \\
\hline $\begin{array}{l}\text { Manusia membutuhkan sumber } \\
\text { daya alam untuk keberlangsungan } \\
\text { hidupnya }\end{array}$ & 6 & $\begin{array}{l}\text { “...Alam memberi sumber kehidupan" (partisipan } \\
17)\end{array}$ \\
\hline $\begin{array}{l}\text { Manusia mengembangkan sains dan } \\
\text { teknologi untuk mempelajari alam }\end{array}$ & 14 & $\begin{array}{l}\text { "Dengan kemajuan jaman dan teknologi manusia } \\
\text { dapat berkembang lebih dan mampu melakukan } \\
\text { penelitian tentang Alam" (partisipan no 5) }\end{array}$ \\
\hline $\begin{array}{l}\text { Manusia mempelajari Alam dari } \\
\text { pengalaman mereka }\end{array}$ & 5 & $\begin{array}{l}\text { "Manusia dapat mengetahui segala sesuatu yang } \\
\text { berkaitan dengan Alam melalui pengalaman..." } \\
\text { (partisipan no 24) }\end{array}$ \\
\hline $\begin{array}{l}\text { Manusia memiliki keterbatasan } \\
\text { dalam mempelajari alam }\end{array}$ & 2 & $\begin{array}{l}\text { "Tidak semua manusia (mampu) mengetahui segala } \\
\text { sesuatu dari Alam...Dibalik berkembangnya } \\
\text { pemikiran manusia dan teknologi, masih banyak } \\
\text { rahasia Alam yang masih perlu untuk } \\
\text { diungkapkan..." (partisipan 1) }\end{array}$ \\
\hline $\begin{array}{l}\text { Manusia mempelajari alam dari } \\
\text { sesama manusia } \\
\text { mengembangkan ilmu pengetahuan }\end{array}$ & 5 & $\begin{array}{l}\text { "Manusia mempelajarinya (Alam) dengan melalui } \\
\text { cara pembelajaran yang dilakukan di sekolah..." } \\
\text { (partisipan 15) }\end{array}$ \\
\hline $\begin{array}{l}\text { Manusia mempengaruhi } \\
\text { kesetimbangan alam }\end{array}$ & 4 & $\begin{array}{l}\text { "Manusia mengetahui segala sesuatu yang berkaitan } \\
\text { dengan Alam...Tetapi (pengetahuan ini) banyak } \\
\text { disalah gunakan seperti pohon ditebang, hutan } \\
\text { dibakar dan limbah dimana-mana" (partisipan 12) }\end{array}$ \\
\hline
\end{tabular}

Ada tujuh kategori respon yang diperoleh melalui analisis refleksi jawaban partisipan terhadap: "Bagaimana dan mengapa manusia mempelajari Alam?" Hal ini berkaitan erat dengan pandangan mereka mengenai manusia ketika dia berperan sebagai individu yang terpisah dari Alam. Ada empat belas respon yang berkaitan dengan kategori yang menyatakan bahwa manusia mengembangkan sains dan teknologi dalam upaya mereka mempelajari Alam. Hal ini mengindikasikan adanya pengakuan dari partisipan bahwa sains dan teknologi merupakan alat yang menolong manusia mengembangkan pengetahuan mereka mengenai Alam. Selain itu respon dengan urutan jumlah terbanyak kedua adalah pada kategori bahwa manusia membutuhkan sumberdaya alam untuk keberlangsungan hidupnya.

Ada sebanyak enam partisipan yang menyatakan hal ini dalam jawabannya, yang melengkapi refleksi mereka dengan pernyataan bahwa hal inilah yang menyebabkan manusia tidak selayaknya memperlakukan Alam dengan sekehendak hati. Berikutnya, ada sebanyak sepuluh partisipan yang mengemukakan dua kategori terpisah, lima pada masingmasing kategori. Mereka berpendapat bahwa manusia dapat mempelajari Alam dari pengalaman mereka sehari-hari dan dari sesama manusia. Karena manusia membagi ilmu pengetahuan yang mereka miliki melalui; contohnya bangku pendidikan, buku, internet 
dan lain-lain.

Kategori berikutnya adalah bahwa manusia memiliki peran dalam mempengaruhi kesetimbangan alam. Ada sebanyak empat partisipan yang menuliskan hal yang sama, dalam bentuk kritik terhadap perilaku manusia yang memanfaatkan pengetahuan mereka semata-mata untuk keuntungan pribadi tanpa memperhatikan kerugian yang dialami oleh Alam. Selanjutnya ada sebanyak empat partisipan mengisi dua kategori terakhir, masingmasing berjumlah dua respon, yaitu manusia memperoleh manfaat dari Alam dan memiliki keterbatasan dalam mempelajari Alam. Partisipan-partisipan ini berpendapat bahwa selain memperoleh sumberdaya yang menolong mereka untuk bertahan hidup, manusia juga mendapat manfaat yang tidak terkira dari Alam, yaitu berupa tempat untuk tinggal dan beraktifitas. Dan dengan memberikan alasan bahwa Alam itu luas cakupannya, partisipan juga menggaris bawahi kelemahan manusia dalam upayanya untuk memahami Alam. Sehingga total ada tiga puluh delapan (38) respon yang tercatat, dikarenakan ada beberapa partisipan yang memiliki respon pada lebih dari satu kategori.

Analisis kedua fokus pada deskripsi partisipan mengenai alam. Kategori-kategori yang muncul dipaparkan dalam Tabel 2. Deskripsi mengenai alam secara epistemology dapat di silangkan dengan kategori mengenai peran manusia di alam. Sama halnya dengan Tabel 1, di dalam tabel ini akan dikemukakan beberapa kategori yang muncul dalam analisis beserta jumlah responden yang mengemukakannya dan contoh kutipan jawaban partisipan.

Tabel 2.

Deskripsi partisipan mengenai Alam

\begin{tabular}{|c|c|c|}
\hline Kategori dan deskripsi & $\begin{array}{l}\text { Frekuensi } \\
\text { respons }\end{array}$ & Contoh kutipan jawaban \\
\hline $\begin{array}{l}\text { Alam adalah tempat tinggal } \\
\text { makhluk hidup dan tak hidup }\end{array}$ & 15 & $\begin{array}{l}\text { "Alam: tempat dimana semuanya bergabung dalam } \\
\text { satu kesatuan yang mencakup benda mati dan benda } \\
\text { hidup dan semuanya saling berkesinambungan yang } \\
\text { membentuk sebuah kehidupan..." (partisipan 13) }\end{array}$ \\
\hline $\begin{array}{l}\text { Alam adalah yang menyediakan } \\
\text { sumber daya untuk kehidupan }\end{array}$ & 4 & $\begin{array}{l}\text { “...Alam menyediakan segala sesuatu yang } \\
\text { diperlukan makhluk hidup..." (partisipan 1) }\end{array}$ \\
\hline Alam adalah ciptaan Tuhan & 7 & $\begin{array}{l}\text { "(Alam) sebuah ciptaan Tuhan yang didalamnya } \\
\text { terdapat makhluk hidup dan benda mati" (partisipan } \\
\text { 11) }\end{array}$ \\
\hline Alam adalah permukaan bumi & 3 & "Alam ialah permukaan bumi..." (partisipan 19) \\
\hline $\begin{array}{l}\text { Alam adalah yang mengisi bumi } \\
\text { (makhluk hidup dan tak hidup) }\end{array}$ & 8 & $\begin{array}{l}\text { "Alam adalah segala sesuatu yang ada di jagat raya, } \\
\text { mengisi bumi" (Partisipan 3) }\end{array}$ \\
\hline Alam adalah lingkungan sekitar & 4 & $\begin{array}{l}\text { "Alam adalah lingkungan yang diciptakan dengan } \\
\text { begitu indah" (Partispan 23) }\end{array}$ \\
\hline $\begin{array}{l}\text { Alam memiliki kekuatan } \\
\text { tersembunyi }\end{array}$ & 1 & $\begin{array}{l}\text { "Alam menyampaikan peringatan kepada manusia } \\
\text { dari bencana-bencana yang timbul karena ulah } \\
\text { manusia" (partisipan 9) }\end{array}$ \\
\hline $\begin{array}{l}\text { Alam tidak selalu dalam keadaaan } \\
\text { konstan }\end{array}$ & 3 & $\begin{array}{l}\text { "...Segala sesuatu Alam dapat terjadi serta berubah- } \\
\text { ubah tanpa diketahui manusia" (partisipan 18) }\end{array}$ \\
\hline
\end{tabular}

Sebanyak delapan kategori respon tercatat pada analisis di Tabel 2. Respon terbanyak adalah pada kategori Alam sebagai tempat tinggal makhluk hidup dan tak hidup. Dari pandangan ini, ada satu partisipan yang memandang Alam murni sebagai tempat mahkluk hidup bernaung, dan membedakan binatang contohnya, sebagai bagian dari Alam. Sebanyak delapan respon tercatat masuk dalam kategori yang menyatakan bahwa Alam 
adalah segala sesuatu yang mengisi bumi. Dalam pandangan ini, partisipan mengacu pada pengelompokan manusia sebagai bagian dari Alam, dan bahwa makhluk tak hidup juga merupakan bagian dari Alam. Istilah 'kesatuan' seringkali muncul dalam pemaparan mereka, yang nampaknya memiliki pandangan holistik dalam memaknai Alam. Selanjutnya ada tujuh partisipan yang menunjukkan hubungan Alam dengan prinsip keagamaan, dimana mereka percaya bahwa Alam adalah ciptaan Tuhan. Figur ini cukup menarik karena ini sebagai penanda sistem kepercayaan yang partisipan anut dan nilai yang mereka jadikan sebagai dasar penentu benar dan salah.

Berikutnya dengan nilai respon yang imbang, sebanyak empat partisipan, muncul dua kategori yang menggambarkan Alam sebagai penyedia sumber daya untuk kehidupan dan Alam yang adalah lingkungan sekitar. Ketika partisipan menyebut sumber daya, mereka juga menyebut bahwa itu diperuntukkan untuk semua makhluk hidup. Tidak ada kesan bahwa partisipan memandang manusia lebih dominan dari spesies lain dan bahwa sumber daya Alam diperuntukkan hanya untuk keberlangsungan hidup manusia saja. Respon yang berimbang juga ditemukan pada kategori Alam adalah permukaan bumi dan tidak selalu dalam keadaan yang sama, sebanyak tiga partisipan. Partisipan dengan pandangan ini mendefinisikan Alam sebagai sesuatu yang mereka dapat temui sehari-hari di luar rumah mereka dan bahwa Alam memiliki sifat yang tidak dapat diperkirakan oleh manusia, dalam hal ini partisipan mengkaitkannya dengan pendapat mereka bahwa manusia memiliki keterbatasan kemampuan dalam memahami kompleksnya Alam. Dan ada satu partisipan, pada kategori 'kekuatan', yang menyiratkan pendapatnya tentang kemampuan Alam dalam memperingatkan manusia yang merusak Alam. Tercatat total ada sebanyak empat puluh lima (45) respon pada dimensi kedua ini, hal ini juga dikarenakan dari total partisipan yang menjawab ada partisipan yang pendapatnya berada pada lebih dari satu kategori.

Analisis mengenai persepsi partisipan mengenai alam dan peran manusia diatas, telah secara tidak langsung menghasilkan sebuah gambaran tentang bagaimana mereka memandang hubungan antara manusia dengan alam. Pertanyaan \#4 dan \#5 digunakan untuk menelaah opini partisipan mengenai interaksi antara manusia dan alam sekitar. Data yang diperoleh dari kedua item ini, juga data yang kemudian ditriangulasikan dengan respon mereka terhadap pertanyaan di item yang lain, di analisis untuk memperoleh kategori pada dimensi 'hubungan' ini (dimensi ke-3). Empat kategori respon pun diperoleh dengan cara ini.

Kategori pertama adalah kategori dengan repons partisipan yang berpendapat bahwa manusia seharusnya 'melindungi' alam. Bagi partisipan dengan pandangan seperti ini, alam adalah objek yang harusnya dimanfaatkan, dipelajari dan dilindungi; pandangan seperti ini menganut paham 'Anthropocentric' atau yang juga disebut human-centered. Kategori ini menempatkan manusia sebagai yang lebih dominan terhadap alam dan menggambarkan Alam sebagai penyedia ssumber daya yang dibutuhkan oleh manusia. Satu partisipan yang memilih pandangan ini, mendeskripsikan bahwa manusia membutuhkan Alam, dan telah mengembangkan teknologi untuk mencoba memahami Alam, dengan tujuan untuk memenuhi kebutuhannya tersebut. Menurutnya walaupun manusia boleh menguasai bumi namun karena Alam menyimpan kekuatan tersembunyi, manusia tetap harus awas dan menjaga Alam dengan bertindak bijaksana ketika mengeksploitasinya.

Sedangkan respons pada kategori kedua adalah 'menghormati', dimana partisipan memiliki pandangan berbeda mengenai bagaimana manusia selayaknya mengikuti aturan Alam. Pandangan ini mengacu kepada paham 'Naturecentric', dimana Alam dianggap memiliki kekuatan yang tidak dapat diprediksi oleh manusia, dan konsep yang dianut yaitu bahwa manusia memiliki keterbatasan pengetahuan dalam memahami Alam. 
Sejumlah total dua belas partisipan memilih posisi 'menghormati' dalam menggambarkan pandangannya mengenai hubungan manusia dan Alam. Dari Tabel 3 dapat dilihat dari antara partisipan-partisipan ini tidak ada yang berpendapat bahwa manusia memperoleh manfaat dari Alam. Serta walaupun mayoritas mereka mengakui bahwa manusia telah mengembangkan sains dan teknologi dalam memahami Alam, mereka berpendapat bahwa manusia berpotensi merusak Alam dengan segala pengetahuan mereka. Penggambaran mereka tentang Alam mayoritas menyatakan bahwa Alam adalah tempat tinggal dan merupakan ciptaan Tuhan.

Selain kedua kategori ekstrem di atas, partisipan juga menggunakan istilah 'hidup berdampingan' untuk menggambarkan hubungan saling membutuhkan antara manusia dengan Alam. Analisis lebih lanjut menemukan bahwa beberapa partisipan menggambarkan hubungan tersebut dengan posisi bahwa Alam harus dianggap sebagai 'sumber kehidupan' yang manusia butuhkan. Dalam kategori ini partisipan menyatakan bahwa manusia tidak dapat dipisahkan dari alam, namun mereka juga bukan sebagai penguasa Alam. Ada sebanyak sembilan partisipan yang memiliki pandangan seperti ini. Sementara partisipan lain menggambarkan hubungan tersebut dengan pandangan yang lebih 'pragmatis'. Dalam kategori ini, delapan partisipan menjelaskan bahwa hubungan antara manusia dengan Alam adalah seperti hubungan dalam sebuah pertemanan, dimana ada saling memberi untuk mendapatkan keuntungan, namun tidak saling bertentangan satu sama lain.

Tabel 3 menyimpulkan respons partisipans terhadap pandangan mereka mengenai peran manusia di Alam (dimensi pertama) dan deskripsi mereka mengenai Alam (dimensi ke-2) di bawah empat kategori pada pandangan mereka mengenai hubungan manusia dengan Alam (dimensi ke-3). Kategori-kategori ini nampaknya secara alami terletak pada suatu rangkaian kesatuan antara Anthropocentric-Naturecentric. Dimana kategori 'hidup berdampingan-pragmatis' berada di posisi lebih dekat pada Anthropocentric, dan 'hidup berdampingan- sumber kehidupan' berada pada posisi lebih dekat pada Naturecentric. Sehingga dapat disimpulkan bahwa secara keseluruhan 30\% partisipan memiliki worldview yang human- centered, sementara $70 \%$ partisipan memiliki worldview yang naturecentered ketika harus menggambarkan pendapat mereka mengenai hubungan manusia terhadap Alam.

\section{Konsep terhadap sifat dasar sains}

Di dalam pertanyaan yang diajukan oleh peneliti, ada enam aspek sifat dasar IPA yang akan digali dari partisipan. Selama proses analisis, pandangan partisipan pada setiap aspek akan secara konstan dibandingkan dengan pembentukan konsep tentang IPA yang terkini. Partisipan secara umum akan diklasifikasikan menjadi 'lebih terinformasi' dan 'naif', berdasarkan apakah mereka memiliki pandangan yang sama (atau tidak) dengan pandangan yang berkembang saat ini. Enam aspek sifat dasar IPA yang akan digunakan sebagai bahan acuan analisis respon partisipan disimpulkan di dalam Tabel 4.

\section{Pilot Study}

Sebelum mewawancarai tiga calon guru sekolah dasar yang telah mengambil bagian dalam mengerjakan kuesioner worldview, peneliti telah lebih dahulu melakukan proses pilot study dengan tiga (3) guru sekolah dasar yang mengajar IPA di kelasnya. Peneliti membutuhkan proses ini untuk mempelajari proses wawancara semi-terstruktur, dan setiap masalah yang muncul selama proses ini akan menjadi bahan refleksi untuk pengembangan item pertanyaan wawancara yang telah disusun sebelumnya. Berikut akan 
dijelaskan terlebih dahulu hasil dari pilot study terhadap guru untuk memahami bagaimana guru yang telah mengajar IPA memaknai IPA itu sendiri. Kemudian akan dilanjutkan dengan hasil refleksi peneliti terhadap hal-hal apa yang perlu dikembangkan pada wawancara berikutnya dengan partisipan yang dari calon guru SD.

Tabel 3.

Frekuensi respon dari persepsi tentang peran manusia dan deskripsi mengenai Alam yang berkaitan dengan pandangan tentang hubungan manusia dengan Alam

\begin{tabular}{|c|c|c|c|c|}
\hline \multicolumn{5}{|c|}{ Pandangan tentang hubungan manusia-Alam } \\
\hline & $\begin{array}{l}\text { Hidup } \\
\text { berdampingan- } \\
\text { pragmatis }(n=8)\end{array}$ & $\begin{array}{l}\text { Hidup } \\
\text { berdampingan- } \\
\text { sumber kehidupan } \\
(n=9)\end{array}$ & $\begin{array}{l}\text { Menghormati } \\
\quad(n=12)\end{array}$ & Total \\
\hline \multicolumn{5}{|l|}{ Persepsi peran manusia } \\
\hline $\begin{array}{l}\text { Memperoleh manfaat } \\
\text { dari Alam }\end{array}$ & 1 & & & 2 \\
\hline $\begin{array}{l}\text { Membutuhkan sumber } \\
\text { daya alam }\end{array}$ & 1 & 2 & 3 & 6 \\
\hline $\begin{array}{l}\text { Mengembangkan } \\
\text { teknologi dan sains } \\
\text { untuk meneliti Alam }\end{array}$ & 3 & 4 & 6 & \\
\hline $\begin{array}{l}\text { Mempelajari Alam dari } \\
\text { pengalaman }\end{array}$ & 1 & 2 & 2 & 5 \\
\hline $\begin{array}{l}\text { Terbatas dalam } \\
\text { memahami Alam }\end{array}$ & 1 & 1 & & 2 \\
\hline $\begin{array}{l}\text { Mempelajari Alam } \\
\text { manusia }\end{array}$ & 2 & 1 & 2 & 5 \\
\hline $\begin{array}{l}\text { Membawa pengaruh } \\
\text { kesetimbangan Alam }\end{array}$ & 1 & 1 & 2 & 4 \\
\hline \multicolumn{5}{|c|}{ Deskripsi Mengenai Alam } \\
\hline Tempat tinggal & 5 & 3 & 7 & \\
\hline Sumber kehidupan & 1 & 2 & 1 & 4 \\
\hline Ciptaan Tuhan & & 2 & 5 & 7 \\
\hline Permukaan bumi & 1 & & 2 & 3 \\
\hline Isi bumi & 2 & 3 & 3 & 8 \\
\hline Lingkungan & 1 & 1 & 1 & 4 \\
\hline Memiliki kekuatan & & & & 1 \\
\hline Berubah-ubah & & 3 & & 3 \\
\hline
\end{tabular}

Tabel 4.

Taksonomi dari pandangan terkini mengenai sifat Dasar IPA

\begin{tabular}{|l|l|}
\hline \multicolumn{1}{|c|}{ Aspek } & \multicolumn{1}{c|}{ Penjelasan/deskripsi } \\
\hline Empiris & Alam itu nyata, dapat diamati dan diuji secara langsung. \\
\hline Sementara & Pengetahuan dalam IPA dpat berubah dan tidak bersifat mutlak ataupun pasti. \\
\hline
\end{tabular}




\begin{tabular}{|l|l|}
\hline Inferensi & $\begin{array}{l}\text { Ada perbedan yang cukup jelas antara hasil observasi langsung dari Alam dan } \\
\text { deduksi atau menyimpulkan sesuatu dari sebuah pengamatan untuk menjelaskan } \\
\text { penyebab sebuah fenomena. Setiap kejadian memiliki penyebab alamiah }\end{array}$ \\
\hline Kreatif & $\begin{array}{l}\text { Observasi dan eksperimen bukanlah satu-satunya sumber dari ilmu pengetahuan } \\
\text { Alam. Kreatifitas manusia dan imajinasi juga berperan dalam menghasilkan } \\
\text { pengetahuan dalam IPA }\end{array}$ \\
\hline Subjektif & $\begin{array}{l}\text { Ilmuan berusaha untuk objektif dan bebas dari nilai-nilai budaya yang dia miliki, } \\
\text { namun sebagai manusia mereka juga dapat menjadi bias dan dipengaruhi oleh } \\
\text { teori, pengetahuan sebelumnya dan kepercayaannya. }\end{array}$ \\
\hline $\begin{array}{l}\text { Metode } \\
\text { Ilmiah }\end{array}$ & $\begin{array}{l}\text { Pengetahuan dalam IPA tidak dihasilkan dengan hanya satu metode penelitian } \\
\text { yang bersifat universal. Ilmuan menggunakan beberapa variasi metode. }\end{array}$ \\
\hline
\end{tabular}

Dari hasil wawancara dengan partisipan guru, peneliti mendapati bahwa nampaknya guru memiliki pandangan yang kurang memadai atau 'naif' terhadap sifat empiris dan inferensi dari pengetahuan dalam IPA. Pandangan ini termanifestasi dalam jawaban mereka ketika diminta menjelaskan tentang IPA. Partisipan menjelaskan bahwa IPA adalah pengetahuan untuk menjelaskan tentang Alam, perbedaan yang dimiliki dengan pengetahuan yang lain adalah pada batasan ini. Ketika pengetahuan ini merambah pada hal mengenai moral, hubungan dengan sesama manusia, contohnya, maka pengetahuan ini bukan merupakan bentuk pengetahuan IPA. Ketika partisipan diminta untuk mengkaitkan IPA dengan epistemologi IPA, mereka menyebutkan tentang observasi dan eksperimen, namun fokus jawaban adalah pada bahwa pengetahuan yang diperoleh melalui kedua cara ini valid jika disertai fakta yang jelas. Pemaknaan terhadap sifat empiris IPA masih pada bahwa IPA adalah kumpulan fakta yang diamati untuk menghasilkan sebuah teori, dan tidak ada partisipan yang menyebutkan mengenai sisi penjelasan logis ataupun kerangka teori dari ilmuan. Hal ini dikonfirmasi lagi dari respon partsipan terhadap sifat inferensi IPA, dimana partisipan diminta pendapatnya mengenai teori atom dan definisi spesies. Mereka cenderung yakin bahwa ilmuan sudah menghasilkan teori yang tidak perlu diragukan lagi kebenarannya, dengan alasan bahwa: (1) teori adalah hasil pengamatan dan eksperimen, yang berarti berdasarkan fakta, (2) tidak ada perdebatan antara sesama ilmuan, yang berarti ilmuan lain pun menemukan fakta yang sama dan relevan.

Namun ketika partisipan diminta untuk menjelaskan mengenai mengapa dalam teori punahnya dinasaurus ada dua penjelasan yang berbeda dari para ahli, mereka mengungkapkan sisi subjektifitas ilmuan. Dalam respon ini, partisipan masuk dalam kategori 'lebih terinformasi' atau memiliki pandangan yang cukup memadai mengenai subjektifitas IPA. Karena kepercayaan pada umumnya IPA adalah objektif, dan selalu berdasarkan bukti nyata. Namun, bertolak belakang dengan pandangan umum, partisipan dalam fase pilot study ini, menjelaskan bahwa ilmuan mungkin menggunakan metode eksperimen yang berbeda dalam menghasilkan teori, yang kemungkinan dipengaruhi oleh cara pandang mereka dan keyakinan mereka terhadap suatu fenomena. Sehingga secara tidak langsung, partisipan menyebutkan bahwa memang ada variasi metode dalam IPA.

Untuk sifat kreatifitas dalam IPA, partisipan memiliki dua pendapat berbeda. Ada yang meyakini bahwa dalam IPA tidak ada unsur kreatifitas dan imajinasi. Namun partisipan lain meyakini hal sebaliknya, dengan mencontohkan bagaimana ilmuan melakukan proses eksperimen yang melibatkan daya imajinasi ilmuan. Kedua respon ini walaupun berbeda, namun masih masuk dalam kategori 'naif'. Karena walaupun partisipan mengakui adanya unsur kreativitas dalam IPA, namun dari contoh yang mereka berikan, mereka hanya mengekspos bagian perencanaan dan pengambilan data eksperimen. 
Dari hasil wawancara pada fase ini, peneliti mempelajari beberapa hal penting seperti penggunaan teknik probing dalam upaya mengklarifikasi jawaban dari partisipan. Selain itu bentuk pertanyaan yang bersifat interogatif juga akan diminimalisir dalam wawancara berikutnya. Untuk itu, jenis pertanyaan yang disampaikan adalah pertanyaan terbuka, yang membuat partisipan bebas merespon sesuai dengan persepsi mereka. Peneliti kemudian akan mengembangkan pertanyaan sesuai dengan respon partisipan. Namun beberapa item pertanyaan inti tetap dipertahankan dalam rubrik wawancara, untuk membuat peneliti tetap fokus pada tujuan wawancara.

\section{Wawancara semi-terstruktur}

Dalam fase ini, lima partisipan dari sampel calon guru yang sebelumnya telah menjawab kuesioner 'worldview' yang diberikan peneliti, diminta kesediaannya untuk diwawancara lebih lanjut. Dengan jumlah sampel yang sedikit, peneliti dapat lebih fokus dalam merespon setiap partisipan sebagai individu, dan proses analisis juga dapat menjadi jauh lebih teliti, mengingat dapat begitu kompleksnya pandangan seorang individu mengenai apa yang dia maknai sebagai IPA.

\section{Sifat empiris IPA.}

Selama wawancara, ketika diminta menjelaskan apa yang mereka pikirkan tentang IPA, partisipan kompak menjawab cakupan ilmu pengetahuan ini yang hanya berkisar tentang Alam, makhluk hidup dan tak hidup. Mereka menyebutkan bahwa pengetahuan dalam IPA diperoleh berdasarkan bukti-bukti nyata di lapangan. Namun mereka juga menekankan pentingnya eksperimen dalam IPA, dimana konsep eksperimen itu sendiri bagi mereka adalah suatu bentuk penelitian yang berupa manipulasi objek. Menariknya ada satu partisipan yang membedakan penelitian dengan eksperimen, dimana dia mengkorelasikan eksperimen dengan suatu kegiatan yang berada di laboratorium:

"Penelitian itu biasanya kita langsung (ke lapangan), umpama penelitian (mengenai)

ikan harus turun ke kolam atau danau. (Sedangkan) eskperimen kan bisa melakukannya di laboratorium".

Dalam menjelaskan mengenai IPA, terlihat bahwa partisipan memiliki pandangan yang kurang memadai mengenai IPA, dimana IPA digambarkan selalu berdasarkan bukti nyata dan erat kaitannya dengan manipulasi objek di dalam sebuah kegiatan di laboratorium.

\section{Metode ilmiah dalam IPA.}

Ketika memaparkan mengenai eksperimen, partisipan menyebutkan juga tentang aturanaturan baku yang ada di dalam proses melakukan eksperimen:

"Apabila ingin mendapat hasil yang baik harus seperti itu pak, karena kan ga bisa

kalau meneliti itu asal-asal diteliti, harus ditentukan dulu prosesnya. Harus ada proses tertentu yang harus dilewati" "Kalau menurut saya punya prosedur tertentu ya...Jadi mereka punya patokan"

Eksperimen dalam pandangan partisipan adalah merupakan suatu kegiatan dengan langkah- langkah yang sudah ditetapkan bersama oleh sesama ilmuan dan universal sifatnya. Hal ini dilakukan supaya hasil yang diperoleh adalah teori yang dapat dinyatakan valid pada akhirnya. Pandangan ini masuk dalam kategori 'naif' jika berbicara mengenai metode ilmiah dalam IPA, karena tidak ada resep pasti langkah per langkah untuk menghasilkan suatu teori yang valid dalam IPA.

\section{Sifat sementara dalam IPA.}

Semua partisipan merespon dengan jawaban bahwa teori dalam IPA ada 
kemungkinan berubah dan berkembang. Beberapa dari mereka memberikan alasan bahwa teori IPA mungkin saja berubah karena: (1) perubahan Alam (2) adanya informasi baru yang ditemukan, (3) perkembangan jaman (teknologi). Pendapat ini masih dianggap kurang memadai ketika mendiskusikan mengapa teori dalam IPA bisa mengalami perubahan. Namun beberapa partisipan juga berpendapat bahwa teori IPA berubah karena ada ide-ide baru dan teori yang berbeda muncul:

"Menurut saya teori yang ada sekarang ini merupakan pacuan kita untuk kedepannya, apakah nanti atom itu teorinya akan berubah atau tidak itu (tergantung) dari teori yang kita pelajari..."

Pandangan ini masuk dalam kateori 'lebih terinformasi' mengenai mengapa bisa terjadi perubahan dalam teori IPA.

\section{Sifat inferensi dari IPA.}

Peneliti memberikan kepada partisipan dua definisi dalam IPA; yaitu definisi spesies dan atom. Semua partisipan nampaknya memiliki pandangan yang 'naif' mengenai bagaimana ilmuan memperoleh kedua definisi ini. Mereka berpendapat bahwa definisi ini dihasilkan dari pengamatan langsung, dan bahwa teori ini jelas terbukti oleh ilmuan manapun. Namun ada beberapa partisipan yang meragukan bahwa manusia bisa mengamati atom secara langsung, dan menyatakan bahwa mungkin saja mereka menggunakan imajinasi mereka saat menggambarkan bentuk atom:

"mungkin itu (model atom) imajinasi orang itu kali ya pak"

Salah satu partisipan walaupun berpendapat bahwa teori IPA selalu berdasarkan hasil pengamatan langsung, namun secara tersirat menjelaskan bahwa teori atom, contohnya, diambil berdasarkan penarikan kesimpulan dari manifestasi suatu fenomena yang bisa diamati langsung:

"Mungkin mereka melakukan percobaan seperti menggesek-gesekkan penggaris dengan rambut lalu ada kertas disobek kecil-kecil. Mereka dekatkan setelah digosokkan ke rambut itu ternyata nempel..."

\section{Kreatifitas manusia dalam IPA.}

Seluruh partisipan mengakui bahwa dalam IPA ada sisi kreatifitas ilmuan. Namun ketika ditelusuri lebih lanjut, di bagian mana menurut mereka ilmuan berkreasi atau berimajinasi dalam proses menghasilkan suatu pengetahuan baru, partisipan merespon bahwa hanya pada bagian eksperimen saja ilmuan melakukannya. Dari pemberian contoh bagian eksperimen yang mereka maksudkan, dapat disimpulkan bahwa menurut mereka adalah pada fase merencanakan, mendesain dan pengumpulan data:

"Menurut saya perlu, tetapi tidak semua memakai imajinasi. Karena kan imajinasi dan kreativias itu untuk seni di bidang seni estetika. Kalau di bidang ilmu pengetahuan menurut saya sesuai keadaan nyata dan buki-bukti yang ada..."

Namun bukan pada bagian dimana ilmuan harus melakukan pengambilan kesimpulan, karena pada bagian ini harus murni dilakukan sesuai data yang diperoleh. Pandangan ini sekali lagi menunjukkan bahwa partisipan dalam penelitian ini masuk dalam kategori 'naif' ketika memandang IPA secara umum.

\section{Pembahasan}

Literature yang berkaitan dengan tema ini (Ogunniyi $d k k$., 1995), memaparkan bahwa guru yang memiliki pandangan tradisional tentang Alam lebih cenderung untuk memiliki konsep yang kurang memadai atau 'naif' mengenai sifat dasar IPA. Dibandingkan dengan 
orang-orang yang memiliki cara pandang yang lebih ilmiah, mereka yang memiliki cara pandang 'tradisional' seringkali didefinisikan sebagai orang yang percaya kepada roh-roh, metafisik, dan menjaga harmoni dengan Alam. Berdasarkan definisi tersebut, hasil yang diperoleh dalam penelitian ini menunjukkan kesesuaian dengan pemaparan Ogunniyi $d k k$ (1995).

Partisipan dalam penelitian ini mayoritas $(70 \%)$ memiliki worldview yang naturecentered, dimana mereka tidak menganggap manusia sebagai yang dominan di Alam. Ketika mereka menyebutkan Tuhan sebagai pencipta, mereka menyebutkan bahwa semua mahkluk hidup dan tak hidup di dunia terhubung satu sama lain, sehingga menjaga kesetimbangan Alam sangatlah penting untuk kehidupan semua elemen. Pandangan ini lebih bersifat holistik.

Pandangan ini sangatlah berbeda dengan pandangan dalam kajian ilmiah, dimana tubuh dan roh terpisah, dan bukanlah satu kesatuan. Sehingga penjelasan mengenai fenomena Alam seringkali dipisahkan dengan hal-hal yang bersifat metafisik, namun seringkali juga muncul dengan istilah pseudoscience. Dan ketika partisipan di wawancara untuk menggali konsep mereka tentang IPA, ditemukan bahwa mayoritas dalam ke enam aspek yang diteliti, partisipan berpandangan kurang memadai atau 'naif' ketika memaknai IPA.

Perbedaan worldview yang dimiliki partisipan ternyata berpengaruh cukup signifikan terhadap bagaimana mereka memaknai IPA. Dengan menyadari bahwa mereka memiliki worldview yang cukup berbeda dengan komunitas ilmiah yang menghasilkan pengetahuan dalam IPA, partisipan dapat mengambil pelajaran penting bahwa hal ini juga dapat mempengaruhi mereka ketika mereka harus mengajarkan IPA di dalam kelas. Secara tersirat, sebagai tenaga pengajar kelak, mungkin saja mereka malah akan memperburuk atau gagal mengkoreksi pembentukan konsep IPA yang kurang memadai pada siswa didik mereka.

Penelitian ini dapat dijadikan sebagai acuan bagi guru dan calon guru untuk memahami pentingnya hal mendasar mengenai kepercayaan siswa tentang dunia berdasarkan budaya yang dimilikinya, dan bagaimana kepercayaan ini di dukung oleh sistem pendidikan, karena pendidikan IPA dapat dikatakan sukses sejauh IPA dapat menemukan kedudukannya yang sesuai dalam konteks kognitif dan sosiocultural anak.

Hasil penelitian ini juga ingin menekankan pentingnya peran seorang guru dalam membuat siswanya sadar mengenai perbedaan antara apa yang mereka ajarkan dan apa yang mereka (guru) sebenarnya yakini. Jika apa yang guru ajarkan dalam pelajaran IPA berbeda dengan apa yang guru yakini benar dan dilakukan di luar sekolah, maka sangatlah tidak rasional untuk membuat asumsi jika siswa dapat secara otomatis berpindah dari cara pandang yang satu ke cara pandang lainnya, ketika harus mempelajari IPA di dalam kelas. Dalam hal ini maka fungsi dari kelas yang sensitif terhadap isu budaya yang dimiliki anak, adalah untuk menjelaskan dan membuat siswa sadar tentang arti dan nilai dari pengalaman sehari-harinya berhadapan dengan fenomena Alam.

\section{KESIMPULAN}

Dari hasil penelitian ini dapat disimpulkan bahwa calon guru IPA di Palangka Raya yang tidak memiliki latar belakang budaya barat, dan yang memiliki budaya Dayak yang kental dalam kesehariannya, ternyata memiliki worldview yang nature-centred. Perbedaan worldview yang mereka miliki nampaknya berimplikasi pada kurang memadainya pembentukan konsep mereka tentang sifat dasar IPA. 


\section{REFERENSI}

Acciaioli, G. (2007). From customary law to indigenous sovereignty: Reconceptualizing masyarakat adat in contemporary Indonesia. The revival of tradition in Indonesian politics. The deployment of adat from colonialism to indigenism, 295-318.

Ahmad, S. (2014). Problematika Kurikulum 2013 dan Kepemimpinan Instruksional Kepala Sekolah. Jurnal Pencerahan, 8(2).

Aikenhead, G. S. (1996). Science education: Border crossing into the subculture of science. Studies in Science Education, 27, 1-52

Aikenhead, G. S., \& Jegede, O. J. (1999). Cross-cultural 'science' education: A cognitive explanation of a cultural phenomenon. Journal of Research in 'science' Teaching, 36(3), 269- 287.https://doi.org/10.1002/(SICI)10982736(199903)36:3<269::AID-TEA3>3.0.CO;2-T

Akena, F. A. (2012). Critical analysis of the production of western knowledge and its implications for indigenous knowledge and decolonization. Journal of Black Studies, 43(6), 599-619. https://doi.org/10.1177/0021934712440448

Anazifa, D., \& Hadi, R. F. (2017). The Integration of Javanese Indigenous Knowledge in Biology Learning Resources Development. In Journal of Physics: Conference Series (Vol. 812, No. 1, p. 012057). IOP Publishing.

Asmar, C., \& Page, S. (2009). Sources of satisfaction and stress among Indigenous academic teachers: Findings from a national Australian study. Asia Pacific Journal of Education, 29(3), 387-401.

Baier, M. (2007). The Development of the Hindu Kaharingan Religion: A New Dayak Religion in Central Kalimantan. Anthropos, (H. 2), 566-570.

Baynes, R. (2016). Teachers' Attitudes to Including Indigenous Knowledges in the Australian 'science' Curriculum. The Australian Journal of Indigenous Education, 45(01), 80-90.

Ben-Zvi Assaraf, O., Eshach, H., Orion, N., \& Alamour, Y. (2012). Cultural differences and students' spontaneous models of the water cycle: A case study of Jewish and Bedouin children in Israel. Cultural Studies of 'science' Education, 7(2), 451-477. https://doi.org/10.1007/s11422-012-9391-5

Bohensky, E. L., \& Maru, Y. (2011). Indigenous knowledge, 'science', and resilinece: What have we learned from a decade of International literature on "Integration"? Ecology and Society, 16(4). https://doi.org/http://dx.doi.org/10.5751/ES-04342160406

Boon, H. J. (2012). Regional Queensland parents' views of 'science' education: Some unexpected perceptions. Australian Educational Researcher, 39(1), 17-43. https://doi.org/10.1007/s13384- 011-0045-5

Boulton, A. J., Panizzon, D., \& Prior, J. (2005). Explicit knowledge structures as a tool for overcoming obstacles to interdisciplinary research. Conservation Biology, 19(6), 2026-2029. https://doi.org/10.1111/j.1523-1739.2005.00314.x

Bourke, B. (2014). The qualitative report positionality: Reflecting on the research process. The Qualitative Report, 19(33), 1-9.

Brown, D. A., Pipe, M. E., Lewis, C., Lamb, M. E., \& Orbach, Y. (2007). Supportive or suggestive: Do human figure drawings help 5-to 7-year-old children to report touch? Journal of Consulting and Clinical Psychology, 75(1), 33. 
Bruck, M. (1999). A summary of an affidavit prepared for Commonwealth of Massachusetts v. Cheryl Amirault LeFave. Applied Developmental Science, 3(2), 110-127.

Cajkler, W., Wood, P., Norton, J., \& Pedder, D. (2014). Lesson study as a vehicle for collaborative teacher learning in a secondary school. Professional development in education, 40(4), 511-529.

Chilisa, B. (2012). Indigenous research methodologies. Thousand Oaks, CA: Sage.

Chinn, P. W. (2007). Decolonizing methodologies and indigenous knowledge: The role of culture, place and personal experience in professional development. Journal of research in science teaching, 44(9), 1247-1268.

Crossan, F. (2003). Research philosophy: towards an understanding. Nurse Researcher, 11(1), 46- 55. https://doi.org/10.7748/nr2003.10.11.1.46.c5914

Davis, N. T., \& Callihan, L. P. (2013). Integral methodological pluralism in 'science' education research: Valuing multiple perspectives. Cultural Studies of 'science' Education, 8(3), 505- 516. https://doi.org/10.1007/s11422-012-9480-5

Dei, G. S. (2013). Critical perspectives on indigenous research. Socialist Studies/Études Socialistes, 9(1)

Feyerabend, P. (2010). Against method $4^{\text {th }}$ ed. London: Verso

Fullan, M.G. (1993). Why teacher must become change agents. The Professional Teacher, 50(6), 12-17

Gadgil, M., Berkes, F., \& Folke, C. (1993). Indigenous knowledge for biodiversity conservation. Ambio, 151-156.

Gardner, R. C. \& Lambert, W. E. (1959). Motivational variables in second language acquisition. Canadian Journal of Psychology, 13, 266-272.

Gardner, R. C. \& Lambert, W. E. (1965). Language, attitude, intelligence, and second language achievement. Journal of Educational Psychology, 56, 191-199.

Gardner, R. C. \& Lambert, W. E. (1972). Attitudes and Motivation in Second Language

Learning.

Newbury House: Rowley Mass

Getty, G. A. (2010). The journey between Western and Indigenous research paradigms. Journal of Transcultural Nursing, 21(1), 5-14.

Giroux, H. (1992). Border crossings: Cultural workers and the politics of education. New York: Routledge Press

Glasson, G. E., Frykholm, J. A., Mhango, N. A., \& Phiri, A. D. (2006). Understanding the earth systems of Malawi: Ecological sustainability, culture, and place-based education. Science Education, 90(4), 660-680.

Glasson, G. E., Mhango, N., Phiri, A., \& Lanier, M. (2010). Sustainability science education in Africa: Negotiating indigenous ways of living with nature in the third space. International Journal of Science Education, 32(1), 125-141.

Gondwe, M., \& Longnecker, N. (2014). Scientific and cultural knowledge in intercultural 'science' education: Student perceptions of common ground. Research in 'science' Education, 45(1), 117-147. https://doi.org/10.1007/s11165014-9416-z

Hamlin, M. L. (2013). "Yo soy indígena": Identifying and using traditional ecological knowledge (TEK) to make the teaching of 'science' culturally responsive for Maya girls. Cultural Studies of 'science' Education, 8(4), 759-776. https://doi.org/10.1007/s11422-013-9514-7

Jenks, C. (1993). Culture. London: Routledge 
Kidman, J., Yen, C.F., Abrams, E. (2013). Indigenous Students' experiences of the hidden curriculum in 'science' education: a cross-national study in New Zealand and Taiwan. International Journal of 'science' and Mathematics Education, 11, 43-64

Kilbourn, B. (2006). The qualitative doctoral dissertation proposal. Teachers College Record, 108(4), 529

Lamb, M. E., Orbach, Y., Hershkowitz, I., Esplin, P. W., \& Horowitz, D. (2007). A structured forensic interview protocol improves the quality and informativeness of investigative interviews with children: A review of research using the NICHD Investigative Interview Protocol. Child abuse \& neglect, 31(11), 1201-1231.

Lavallée, L. F. (2009). Practical application of an Indigenous research framework and two qualitative Indigenous research methods: Sharing circles and Anishnaabe symbol-based reflection. International journal of qualitative methods, 8(1), 21-40.

Lee, H., Yen, C. F., \& Aikenhead, G. S. (2012). Indigenous elementary students' Science instruction in Taiwan: indigenous knowledge and western Science. Research in Science Education, 42(6), 1183-1199.

Lewis, C. (2002). Lesson study: A handbook of teacher-led instructional change. Philadelphia: Research for better schools, Inc.

Li, T. M. (2000). Articulating indigenous identity in Indonesia: Resource politics and the tribal slot. Comparative studies in society and history, 42(01), 149-179.

Lowan, G. (2012). Expanding the conversation: Further explorations into Indigenous environmental 'science' education theory, research, and practice. Cultural Studies of 'science' Education, 7(1), 71-81. https://doi.org/10.1007/s11422-012-9379-1

Mack, E., Augare, H., Cloud-Jones, L. D., Davíd, D., Gaddie, H. Q., Honey, R. E., ... Wippert, R. (2012). Effective practices for creating transformative informal 'science' education programsgrounded in Native ways of knowing. Cultural Studies of 'science' Education, 7(1), 49-70. https://doi.org/10.1007/s11422-0119374-y

Mazzocchi, F. (2006). Western science and traditional knowledge. EMBO reports, 7(5), 463-466. Miles, M. B., \& Huberman, A. M. (1994). Qualitative data analysis: An expanded sourcebook. Sage.

Ministry of Education and Culture. (2013). Curriculum 2013. Retrieved from https://urip

Moller, H., Berkes, F., Lyver, P. O. B., \& Kislalioglu, M. (2004). Combining science and traditional ecological knowledge: monitoring populations for co-management. Ecology and society, 9(3).

2. Online at http://www.ecologyandsociety.org/vol9/iss3/art2/

Morrow, S. L. (2005). Quality and trustworthiness in qualitative research in counseling psychology. Journal of counseling psychology, 52(2), 250.

Mpofu, V., Otulaja, F. S., \& Mushayikwa, E. (2014). Towards culturally relevant classroom 'science': A theoretical framework focusing on traditional plant healing. Cultural Studies of 'science' Education, 9(1), 221-242. https://doi.org/10.1007/s11422-013-9508-5

Nakashima, D., Roue, M. (2002). Indigenous knowledge, people and sustainable practice.

Encyclopedia of Global Environmental Change, 5, 314-324

Nakata, M. (2002). Indigenous knowledge and the cultural interface: Underlying issues at the intersection of knowledge and information systems. IFLA journal, 28(5-6), 281-291. 
Safitri, M.A \& Bosko, R.E. (2002). Indigenous people/ethnic minorities and poverty reduction indonesia. Manila: Asian Development Bank

Saher, P.J. (1969). Eastern wisdom and western thought: a comparative study in the modern philosophy of religion. London: Allen \& Unwin

Salirawati, D; Wismono, J; Riyanto. (2010). Gembira Belajar IPA 1. Jakarta: Pusat Perbukuan, Kementrian Pendidikan Nasional.

Saito, E., Harun, I., Kuboki, I., \& Tachibana, H. (2006). Indonesian lesson study in practice: Case study of Indonesian mathematics and science teacher education project. Journal of In-service Education, 32(2), 171-184.

Settlage, J., \& Southerland, S. A. (2007). Teaching science to every child: Using culture as a starting point. Taylor \& Francis.

Sillitoe, P. (1998). The Development of indigenous knowledge. Current Anthropology, 39(2), 223-252. https://doi.org/10.1086/204722

Suja, W, (2011). Analisis kebutuhan pengembangan buku ajar sains SD bermuatan pedagogi budaya Bali. Jurnal Pendidikan dan Pengajaran, 44 (1), 84-92

Suratno, T. (2012). Lesson Study as Practice: An Indonesian Elementary School Experience. Online Submission.

Sutherland, D., \& Swayze, N. (2012). The importance of place in indigenous 'science' education. Cultural Studies of 'science' Education, 7(1), 83-92. https://doi.org/10.1007/s11422-011-9371-1

Tacconi, L., Moore, P. F., \& Kaimowitz, D. (2007). Fires in tropical forests-what is really the problem? Lessons from Indonesia. Mitigation and adaptation strategies for global change, 12(1), 55-66.

Thomas, G. (2009). How to do your research project: A guide for students in education and applied social 'science's. London: SAGE Publication Ltd

Thomas, G. (2011). How to do your case study. London: SAGE Publication Ltd.

Thomson, L. K. (2000). The effect of the Dayak worldview, customs, traditions, and customary law (adat-istiadat) on the interpretation of the Gospel in West Kalimantan, Indonesian Borneo. DMin thesis, Acadia University, 122.

Yin, R. K. (2014). Case study research: Design and methods. Sage publications. 